\title{
Consequences of infant adoption in Taiwan, 1906-1945: The impact of regional context and household composition on child mortality
}

\begin{abstract}
Tim Riswick
(t.riswick@let.ru.nl)

Radboud Group for Historical Demography and Family History, Radboud University, the Netherlands

Abstract: Little is known about health outcomes after adoption in historical non-Western settings and previous studies have found contradictory results of the influence of adoption on mortality risks. This study investigates if, and how, adoption of infants increased child mortality risks compared to nonadopted children. Moreover, it goes further than existing studies by investigating if, and how, after adoption, household composition and regional context influenced child mortality risks of these adopted children in Taiwan during the period 1906-1945. It uses the Taiwan Historical Household Register Database to answer these questions, estimating univariate and multivariate Cox proportional hazard models. The study demonstrates that child mortality risks of both male and female adopted children were much higher compared to non-adopted children. After adoption, household composition was especially important for adopted girls. In particular, similarly aged siblings increased child mortality risks of girls, indicating that the adoptees suffered the consequences of a reallocation of resources. The negative effect of infant adoption on child mortality was the same in all regional contexts. In sum, household composition and regional context should be taken into account when investigating child mortality risks, or other indicators of health inequalities, of adopted children.
\end{abstract}

Acknowledgements: The sources of Japanese household registers in Taiwan used in this paper are partly collected by: Hsiang-Shui Chen (Jiuru), Paul Katz (Donggang), Ying-Chang Chuang (Zhubei \& Emei). Those registers were digitised as the "Taiwan Historical Household Registers Database, 1906-1945" (THHRD) by the Program of Historical Demography, Research Center for Humanities and Social Sciences, Academia Sinica, and contributed to this paper. Furthermore, this article has benefited from meticulous and insightful critiques provided by xxx anonymous reviewers. Members of the Radboud Group for Historical Demography and Family History at Radboud University and members of the Program of Historical Demography at Academia Sinica provided valuable comments. Theo Engelen and Hilde Bras in particular helped to improve this paper by providing key suggestions. This work was supported by The Netherlands Organisation for Scientific Research (NWO) Graduate Programme under Grant [022.002.003] and the Neys-Van Hoogstraten Foundation under Grant [TW266].

Keywords: Child Adoption; Child Mortality; Resource Dilution; Sibling Composition; Taiwan

Word count: 8.528 (excluding references) 


\section{Consequences of infant adoption in Taiwan, 1906-1945: The impact of regional context and household composition on child mortality}

\section{Introduction}

Adoption plays an important part in many societies, both historical and contemporary, for several reasons (Fauve-Chamoux, 1998; Goody, 1969). The different circumstances in these societies are likely to influence the wellbeing of adopted children because of the varying effects of possible biological and psychological consequences for the adopted child and the (re)allocation of tangible and intangible resources within a household. These resources include finances, goods, food, parental attention, care and time. Although little is known about health outcomes after adoption in historical non-Western settings, a way to study the effect of adoption on wellbeing for historical societies is the investigation of mortality risks, as the circumstances under which people die reflects how they have lived (Mattison et al., 2015). In this article, child mortality risks of adopted children (1-5 years) in Taiwan during the period 1906-1945 are investigated. During this period, we know that child mortality was relatively high, adoptions were frequent, and we have detailed information on the life courses of a total of 47,722 children, of which 4,857 children were adopted before the age of one. This information is available from reliable longitudinal and continuous data of the Taiwan Historical Household Register Database (Dong et al. 2015). It makes it possible to study how adopted children are influenced by adoption itself and by the conditions after adoption.

Previous studies have found contradictory results of the influence of adoption on mortality risks. On the one hand, adoption seems to increase mortality risks, while on the other it has a protective effect. This study goes beyond these studies by including the household and regional context in which adopted children lived their lives after adoption to study their health until the age of five. By doing so, our study contributes in several innovative ways to the literature on adoption and health. Firstly, by only focusing on child mortality (between 1 and 5 years) this study examines the general age period in child mortality research, while it is able to really focus on the short-term differences in mortality risks between nonadopted and adopted children. No other study focused on child mortality of adopted children before, while the investigation of young children is particularly valuable because they are part of the most vulnerable groups in a household, being fully dependent on resources of the household. Moreover, for this approach only the most vulnerable children are investigated, namely those who were adopted as infants (i.e. before the age of one).

Secondly, this study examines mortality risks of adopted infants more closely by looking at the specific household context. In other words, it starts from the perspective of household composition, especially sibship size and composition, and goes on to investigate in what ways resource dilution might play a role. By doing so, this study connects with the more general demographic, economic and evolutionary literature on the resource dilution hypothesis and the quantity-quality trade-off model by 
focusing on the specific group of adopted children who might be treated differently from non-adopted siblings, possibly resulting in deprivation or malnutrition. Although this did not directly kill children, it made them more vulnerable to diseases and this in turn may have caused them to die earlier.

Lastly, this study supplements our limited knowledge of the consequences of adoption on health within different regional historical Asian societies. As the nature of adoption differed in southern and northern Taiwan, these dissimilarities are used to analyse whether regional variation in adoption practices also affected mortality risks after adoption differently. Moreover, for northern Taiwan a differentiation can also be made between rural and urban areas to investigate the impact of modernisation and urbanisation. In short, this study positions the consequences of adoption for health in the context of both household and region.

The remainder of the article is organised into four sections. In the first section, the previous literature investigating the consequences of adoption for health outcomes is briefly introduced. In addition, literature on the importance of household composition and regional context for mortality studies is discussed in relation to adoption. In the second section, the data, measurements, and methods used in this study are described. In the third section, the results of the effect of adoption on child mortality are presented first. Then differences in mortality risks within the group of adopted children when looking at household composition and regional context are described. Finally, a conclusion is given which argues that adoption as an infant increased child mortality risks, and that household and regional context also matter for the survival of adopted children. This is important for understanding how inequalities in health were shaped in the past, but may also give an indication of how adoption, and household composition after adoption, may influence other forms of health/social inequalities (albeit ones less extreme than death).

\section{Background}

\section{Earlier findings of adoption on health outcomes}

In historical Asian contexts adoption was an integral part of family life and the demographic system. Individuals and households tried to ensure family continuity through adoption by any means possible if producing children of one's own did not happen for whatever reason. In addition to this, adopted children could also provide essential labour, support in old age, or a way to create alliances between families (Fauve-Chamoux, 1998; Saso, 1999; Waltner, 1990). In general adopted children might therefore be expected to be favoured because parents who adopt consciously choose to do so and see their adopted children as valuable. Moreover, adoption, especially of boys, could also be favourable for the adopted children themselves, as it provided a chance to be the central figure in their new family, and in some cases this even resulted in upward social mobility (Feng and Lee, 1998; Kurosu and Ochiai, 1995). Still, there may be less parental investment in adopted children than in one's own, as one's biological children may receive a preferential treatment over adopted children (Gibson, 2009). 
In Taiwan there was a specific adoption practice to ensure future marriages and family continuity, in which young girls were adopted as a future bride for a son in a so-called minor marriage. ${ }^{1}$ In this way an expensive normal marriage could be avoided and a so-called little daughter-in-law could be raised according to the wishes of her new mother-in-law. Additionally, when no son was present, a girl might be adopted due to the belief that when a future wife was already present a son would soon be born; an adopted daughter could also act as an insurance against childlessness. The adoption of boys was less frequent (less than 10 percent of adoptions), and they were mostly adopted as heirs when biological sons were absent or when they were needed for their (future) labour. This low number was mostly the result of son preference, as sons would directly contribute to the lineage. Yet, for households, the motivation to adopt differed by region as regards to the taking in and giving away of children through adoption (Saso, 1999; Wolf and Huang, 1980; Wolf, 1972). This is, for example, reflected in the frequency of being given away for adoption before age fifteen, which ranged from 45 to 66 percent of girls in northern Taiwan, compared to 12 to 17 percent in southern Taiwan (Chuang and Wolf, 1995). Partly this is due to the varying perceived economic value of women for agricultural labour in these regions (Olds, 2006; Pasternak, 1983). Moreover, the motivation of adoption also differed, depending on whether or not the adopting couple already had one or more non-adopted children.

The first studies investigating the health effects of adoption in Haishan in northern Taiwan in the early twentieth century found that being adopted as an infant was detrimental to adopted daughters, who suffered nutritional deprivation, beatings, and consequently higher mortality by age fifteen. ${ }^{2} \mathrm{~A}$ later study looking at Lungtu in southern Taiwan observed that adopted girls below the age of one had higher mortality risks than non-adopted girls. When comparing these results with Haishan, it is clear that in both localities the same observation can be made, but that the difference between adopted and nonadopted girls was only significant in Haishan. This difference is explained by pointing out that girls in Lungtu might be healthier to begin with, due to the fact that there was more choice in the selection of the child who would be adopted, as adoption was not as frequent compared to the Haishan region. As a result, mostly healthy girls would be adopted (Pasternak, 1983). A more elaborate study of Haishan, which covers the whole life-course of adopted girls, shows that between the ages of one and four adopted

\footnotetext{
${ }^{1}$ Most marriages in Taiwan can be classified as belonging to one of three types: major, minor and uxorilocal. Marriages performed in the major fashion were probably most common in Chinese societies as this was the 'proper' way to marry. Another type of marriage was the minor form. In a minor marriage, a sim-pua, or little daughter-in-law, would be adopted into the family at a very young age to be a future bride for a son of the couple adopting her. The main difference between a major and minor marriage was therefore the timing and the ceremonial complexity of the marriage, which also resulted in lower costs. The third and final form found was uxorilocal marriage. While in most cases the daughter left her family to join her husband's family, in this form of marriage the husband married into the bride's family (Wolf and Huang, 1980).

${ }^{2}$ In recent decades, many researchers have investigated adoption in contemporary societies and found both negative and positive results for a great diversity of outcomes, including child wellbeing. It is important to note, however, that when most (contemporary) studies are taken together they suggest that the cultural, economic and social context determines the motivation and frequency of adoption. In turn the wellbeing of adopted children is affected too (Brown et al., 2017; Howell, 2009; Palacios and Brodzinsky, 2010).
} 
girls' likelihood of dying was almost twice that of a non-adopted daughter. However, their chances of survival were greater than those women reared as non-adopted daughters after the age of twenty. This might be caused by a selection effect of the less healthy dying earlier (Wolf, 1995: 298-318). The negative effects of adoption are confirmed by analysing data from the Penghu Islands for infant mortality (Yu et al., 2011) and reanalysing data from Haishan for child mortality until age five (Riswick, 2013).

Some recent studies, however, have challenged the previous findings of adoption being detrimental for survival in historical Taiwan by taking the whole life course of children adopted between six months and fifteen years old into account. This approach is one of the major ways in which these studies differ from earlier ones, next to that it studies children not from adoption, but from birth onwards. The authors argue that most previous studies were limited geographically and ethnically, and did not control for important covariates that may have mediated the relationship between mortality and adoption such as region, sex of child, parity and socioeconomic status. Therefore, they perform longitudinal analyses of a larger set of data by including adoption as a time-dependent covariate in Cox proportional hazard models. Their findings demonstrate that the adoption of girls does not increase the risk of mortality and is either protective or neutral with respect to mortality (Mattison et al., 2015). A later study investigating mortality differences within the group of adopted daughters demonstrates that the protective effects of adoption were stronger among adopted daughters who were not adopted with the intention of perpetuating the family line, compared to those who were adopted as little daughters-in-law (Mattison et al., 2018). ${ }^{3}$

\section{The (possible) importance of household composition and regional context}

Many studies have shown the importance of the composition of the household for the health of young children because of its influence on the (unequal) distribution of resources (Campbell and Lee, 2004; Oris et al., 2004). Several studies demonstrate the importance of the mother for the survival of her children (Van Poppel, 2000), while the effect of the father depends on household structure and historical context (Derosas and Oris, 2002). Next to parents, other kin might also be important for survival. The presence of maternal grandmothers, for example, often has a positive effect on child survival rates. Although there is much variation, having at least one relative - apart from the mother - seems to be beneficial for child survival in almost all populations (Kramer, 2010; Sear and Coall, 2011; Sear and Mace, 2008). Siblings may, in that sense, play an important role too (Öberg, 2017; Riswick and Engelen, 2018).

This study connects with the literature on the (conditional) resource dilution model, which suggests that there is a negative relationship between the number of children and the amount of resources

\footnotetext{
${ }^{3}$ A recent study focusing on Japan found that adopted boys enjoy survival advantages compared with biological children, especially early in childhood, while adopted girls suffer from elevated mortality risks, especially at later in childhood (Dong and Kurosu, 2019).
} 
that any one child can obtain because resources are finite (Downey, 2001). The effect of this negative relationship can, however, be conditional on the age, gender and sibling position of a child. This is important to acknowledge, since most households are highly stratified, with multiple overlapping hierarchies causing inequality among its members in resource allocation (Folbre, 1986; Klep, 2004; Wolf, 2005). Next to household hierarchies, the extent to which resource dilution plays a role also depends on the level of support given to children by other interested parties, such as household members and institutions like the government, since the provision of resources is not solely the concern of parents. Moreover, this reallocation of resources is also influenced by differences in family systems (Bras et al., 2010; Skinner, 1997). Therefore, specific allocation of resources is often conditional on the specific historical and geographical context and gender preferences, including variations in child-rearing practices and the specific roles of kin and non-kin (Gibbs et al., 2016; Kalmijn and van de Werfhorst, 2016; Riswick, 2018). Because this differs across time and place, it may also explain why the effects of resource dilution are observed for a variety of demographic outcomes in some societies, but not in others.

The question is how household composition affected child mortality risks of adopted children in Taiwan, as they can be viewed as different from non-adopted children. One could argue that a couple (or household) choose to adopt a child and may therefore value it more. Moreover, the motivation for people to adopt children is most often connected with the necessity of doing so. For example, a couple may be childless and the adopted child is the only way for them to continue their lineage and/or have someone to support them in their old age. Yet, a clear distinction should be made on the basis of gender: whereas non-adopted and adopted boys were normally favoured in every household, adopted girls were often seen as inferior (Wolf, 1972). Household composition may in that sense be even more important for adopted children, since it determined their position in the household, and the consequences regarding resource allocation resulting from it, even more. Having no siblings meant that the adopted child did not have to compete with others for the same resources. In contrast, having siblings automatically meant that adopted children were faced with the negative consequences of resource dilution, or in the case of adopted girls, even received detrimental treatment as a result. ${ }^{4}$ In sum, instead of looking only at adoption and kind of adoption, this study uses information on who else is in the adopting household to make assumptions about mortality risks.

Next to household context, this study also addresses questions concerning the influence of regional context on the effect of adoption on child mortality and on the effect of household composition on child mortality after adoption. This is important as economic conditions and cultural norms varied

\footnotetext{
${ }^{4}$ This is also reflected in how an interviewed adopted girl spoke about her lived reality: "she [an adopted girl] is always a little lower than a real daughter (...) unless her foster mother has no other children" (Wolf and Huang 1980:236). Moreover, it is also in line with other contemporary studies that argue that what matters for the wellbeing of adopted children is not only adoption itself, but if there are other children present (Santos-Nunes et al., 2018).
} 
between regional contexts with regard to household formation, modernisation and urbanisation that influenced daily lives. In other words, social relationships, kinship organisation and the way in which adopted children are valued and treated may also vary as a result of regional norms, beliefs, rights and obligations about households and the roles of specific household members (Skinner, 1997). An initial example, which has already been mentioned, is that the adoption of girls was very common in northern Taiwan, indicating that giving away (unwanted) children was much easier and normalised as it was part of the household system. This suggests that on the one hand in northern Taiwan households could choose to give away a child when resources were limited, and on the other hand that more adopted siblings were present who might compete with each other in the same way as non-adopted siblings. This is in contrast to southern Taiwan, where adopted siblings may have faced less competition because adoption was not the norm. It was a conscious choice to adopt and in turn these children may also have been valued more (Chuang and Wolf, 1995). A second example of differences in regional context may be found in the most commercialised and urbanised areas, which later grew into Taipei City in the nineteenth century. The economy of these places offered women and children the opportunity to use their labour outside the household for wages in small-scale production and commerce, handicraft industries, and prostitution (Gates, 1987; Lin, 2011). This meant that in urban households parents could use their parental authority over their children differently from rural parents, and might make different decisions regarding resource allocation (Engelen and Wolf, 2006; Wolf and Gates, 2005). For instance, older sisters may have competed for more resources within the household as parents may have perceive them as valuable because of the opportunities they had to work for wages outside of the household.

\section{Hypotheses}

To offer a new perspective and try to understand the contradictory findings of previous studies, this study focuses on boys and girls who were adopted as infants and their mortality risks as young children (between one and five years old). Firstly, because this study investigates child mortality (between one and five years) of adopted infants, it is expected that this group will be more likely to experience negative effects of adoption as most of the protective effects only become visible at later ages in previous studies (H1). Secondly, according to the resource dilution hypothesis, adopted children who are adopted by a childless couple should have higher survival chances compared to the situation where there are other (non-adopted or adopted) children present. This effect may be stronger for adopted girls because of the values and practices of son preference. Moreover, the negative effect of having siblings may also be conditional on age, as that too influences resource dilution (H2). Thirdly, the specific regional context may cause the effect of adoption on child mortality, and the effect of household composition on child mortality, to vary between areas. This may be caused by the different nature of adoption in rural northern and southern Taiwan, and the effect of modernisation and urbanisation (H3). 


\section{Data, Measurements and Methods}

Taiwan was ruled by Japan from 1895 to 1945, and in 1905 the Japanese colonial government began to implement a household registration system administered by the police to tightly monitor and control the Taiwanese population. Under this registration system, every person had to register with the police as a member of one household. The information required for the household register included many personal details, demographic events, and exact dates of these events for all household members. Household heads had the responsibility of reporting any changes to a local police station, and the police would pay regular and irregular home visits to make sure that the information in the registers was accurate. These household registers, containing considerable demographic details at the individual level, have mostly been preserved to the present and are considered very reliable (Dong et al., 2015; Li et al., 2011; Wolf and Huang, 1980). They offer us the possibility of following individuals on a day-to-day basis. This is key, since, in a pre-transitional society, household composition differed greatly due to high mortality, adoption, marriage, and migration. To be able to take this into account is a major strength of the current study.

Data from a total of 18 study sites are transcribed into the Taiwan Historical Household Registers Database (THHRD), which provides a large population sample for historical demographic analysis (see Figure 1). The sample of the THHRD for this study consists of all children who were born or adopted into a household between 1906 and 1940 from the research areas of Mengjia and Taodaocheng (1), Zhubei (04), Beipu (05), Emei (06), Guanxi (07), Danei (13), Jibei (14), Donggang (15), and Jiuru (16). ${ }^{5}$ It is important to note that all non-adopted and adopted children from each household are selected as research persons, which means that observations are clustered within households. A further selection was made by only including children who survived their first year of life, and are observed from that time onwards. It means that only children who were adopted as infants (before age one) are included in the analyses. This is about 54 percent of the children who were adopted before age five, as most children were adopted when they were between two and eight months old (see Appendix A1 \& A2). These selections were made in order to be able to study the impact of adoption on young child mortality (between 1 and 5 years old). ${ }^{6}$

\footnotetext{
${ }^{5}$ These are the sites that are located in northern and southern Taiwan that were made accessible for this research by the board of the Program for Historical Demography.

${ }^{6}$ There is also a difference with the dataset in this paper compared to (Mattison et al., 2015) because it is the latest version of the Taiwan Historical Household Register Database in which more information is entered. For example, the Guanxi region is not included in their articles.
} 
Figure 1: Map of the research sites of available in the THHRD

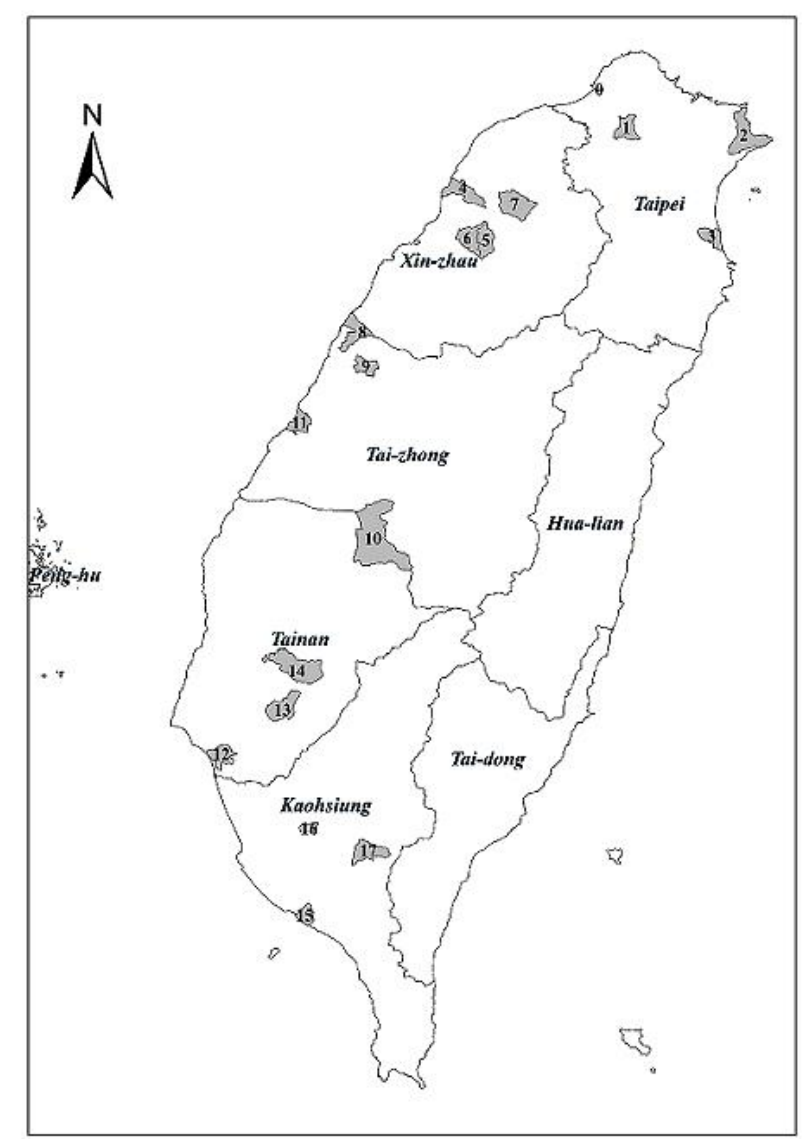

The research sites selected for this study are: Meng-jia \& Tao-dao-cheng (1), Zhubei (04), Beipu (05), Emei (06), Guanxi (07), Danei (13), Jibei (14), Donggang (15), and Jiuru (16). Source: Program for Historical Demography, Research Center for Humanities and Social Sciences, Academia Sinica.

Univariate analyses are carried out by employing Kaplan-Meier survival curves, while multivariate event history Cox proportional hazard models analyse child mortality risks by taking timevarying and control variables into account. Observation time begins at day 366 (age one) for a child and ends when the child dies (failure event) before his or her fifth birthday. All remaining children (which are research persons) are censored after their fifth birthday, or earlier when they could no longer be observed. The observations are clustered by household identity number. Hence, models with robust standard errors were estimated to adjust for intra-household correlation. Kaplan-Meier curves are presented in Figures 2 and 3. Cox proportional hazard models are presented in Table 2 to examine the effect of adoption on child mortality risks. In Tables 3 and 4, Cox proportional hazard models are presented to investigate the effect of household composition, especially sibling composition, on the 
mortality risks of adopted children. ${ }^{7}$ Probability values of less than 0.10 are assumed to represent statistical significance because of low numbers, although attention is also paid to effect sizes and confidence intervals of non-significant variables. ${ }^{8}$

In Table 2, the main variable of interest regarding child mortality is whether or not a child is adopted. In Tables 3 and 4, the main independent variables of interest are the presence of adopted and non-adopted brothers and sisters in different age categories. These are coded as dummy variables: having a sibling present (0-1). Siblings are defined as having the same father or mother as the adopted research person, while adopted siblings are defined as having been adopted by the same adoptive father or mother of the adopted research person. It is important to note that the presence of co-resident siblings is treated as a time-varying covariate. This accommodates the fact that siblings could move in and out of the household while the adopted research person was growing up. In addition, the presence of siblings is divided into age categories compared to the age of the research person: up to five years older, and more than five years older. These groups are based on the assumption that the age difference between siblings who are present and the research person may be of importance for the allocation of certain resources (Kippen and Walters 2012; Riswick and Hsieh forthcoming). Gender and adoption are also included by explicitly looking at the presence of adopted and non-adopted brothers and sisters in each age category. Lastly, the relatives who have the most important influence on child mortality according to the literature - namely the parents and grandparents - are also included as time-varying variables. Next to these main variables, other variables are included as co-variates. The occupation of the household head and the ethnicity are added to control for economic conditions and cultural norms. By including the region and time period it is possible to control for differences in time and place.

The summary statistics of all variables - measured at the moment when the non-adopted and adopted research persons were aged one - are presented in Table 1. In general, both groups are comparable with regard to socio-economic status. There are, however, some differences which may also influence the effects of certain determinants of child mortality risks. As previously mentioned, adopted children are mostly girls, and most adoptions took place in the northern regions in Taiwan. In addition, in the later period (1926-1940) fewer adoptions took place and the Chinese Hakka and Hokkien ethnic groups adopted more children than other ethnicities. All of this is in line with the findings of previous studies. Lastly, compared to non-adopted children, adopted children were more frequently found in

\footnotetext{
7 The impact of sibling composition - differentiating between gender, age categories and adoption status - for infant and young child mortality (0-5 years) of non-adopted children is investigated in Riswick \& Hsieh (forthcoming).

${ }^{8}$ Diagnostics were run to check whether all assumptions were met and adjusted when needed. In most cases the variables were not violating the proportional hazard assumption, and when the assumptions were not fully met other models were run with time-interactions. These models confirmed the same qualitative conclusions and were in line with the results presented.
} 
households where couples did not have any children, or where the mother was absent. The latter situation is common, as it enabled widowed men to secure, for instance, old-age support.

Table 1: Descriptive statistics of research persons at age one in the selected research areas in Taiwan,

1906-1940

\begin{tabular}{|c|c|c|c|c|}
\hline \multirow{2}{*}{ Variables } & \multicolumn{2}{|c|}{ Non-adopted } & \multicolumn{2}{|c|}{ Adopted } \\
\hline & Number & $\%$ & Number & $\%$ \\
\hline $\begin{array}{l}\text { Sex } \\
\text { Male } \\
\text { Female }\end{array}$ & $\begin{array}{l}22769 \\
20096\end{array}$ & $\begin{array}{l}53.1 \\
46.9\end{array}$ & $\begin{array}{c}737 \\
4120\end{array}$ & $\begin{array}{l}15.2 \\
84.8\end{array}$ \\
\hline $\begin{array}{l}\text { Sibling composition } \\
\text { None } \\
\text { Only Sisters } \\
\text { Only Brothers } \\
\text { Sisters and Brothers }\end{array}$ & $\begin{array}{c}10478 \\
8888 \\
7738 \\
15782 \\
\end{array}$ & $\begin{array}{l}24.4 \\
20.7 \\
18.1 \\
36.8 \\
\end{array}$ & $\begin{array}{c}1514 \\
879 \\
1070 \\
1394 \\
\end{array}$ & $\begin{array}{l}31.2 \\
18.1 \\
22.0 \\
28.7\end{array}$ \\
\hline $\begin{array}{l}\text { Mother } \\
\text { No } \\
\text { Yes }\end{array}$ & $\begin{array}{c}486 \\
42400\end{array}$ & $\begin{array}{c}1.1 \\
98.9\end{array}$ & $\begin{array}{c}337 \\
4520\end{array}$ & $\begin{array}{c}6.9 \\
93.1\end{array}$ \\
\hline $\begin{array}{l}\text { Father } \\
\text { No } \\
\text { Yes }\end{array}$ & $\begin{array}{c}2382 \\
40504 \\
\end{array}$ & $\begin{array}{c}5.6 \\
94.5\end{array}$ & $\begin{array}{c}287 \\
4570 \\
\end{array}$ & $\begin{array}{r}5.9 \\
94.1 \\
\end{array}$ \\
\hline $\begin{array}{l}\text { Grandmother } \\
\text { No } \\
\text { Yes }\end{array}$ & $\begin{array}{l}22962 \\
19924\end{array}$ & $\begin{array}{l}53.6 \\
46.5\end{array}$ & $\begin{array}{l}2714 \\
2143\end{array}$ & $\begin{array}{l}55.9 \\
44.1\end{array}$ \\
\hline $\begin{array}{l}\text { Grandfather } \\
\text { No } \\
\text { Yes }\end{array}$ & $\begin{array}{l}26183 \\
16703\end{array}$ & $\begin{array}{l}61.1 \\
39.0\end{array}$ & $\begin{array}{l}3423 \\
1434\end{array}$ & $\begin{array}{l}70.5 \\
29.5\end{array}$ \\
\hline $\begin{array}{l}\text { Occupation head } \\
\text { Farmers } \\
\text { Low SES } \\
\text { High SES } \\
\text { Unknown }\end{array}$ & $\begin{array}{c}27679 \\
5244 \\
3883 \\
2107\end{array}$ & $\begin{array}{c}64.6 \\
12.2 \\
9.1 \\
14.1\end{array}$ & $\begin{array}{c}3311 \\
444 \\
377 \\
725\end{array}$ & $\begin{array}{c}68.2 \\
9.1 \\
7.8 \\
14.9\end{array}$ \\
\hline $\begin{array}{l}\text { Ethnicity } \\
\text { Hokkien } \\
\text { Hakka } \\
\text { Other } \\
\end{array}$ & $\begin{array}{c}10346 \\
24577 \\
7942 \\
\end{array}$ & $\begin{array}{l}24.1 \\
57.3 \\
18.5 \\
\end{array}$ & $\begin{array}{c}1777 \\
2647 \\
433 \\
\end{array}$ & $\begin{array}{c}36.6 \\
54.5 \\
8.9 \\
\end{array}$ \\
\hline $\begin{array}{l}\text { Period } \\
1906-1925 \\
1926-1940\end{array}$ & $\begin{array}{l}22765 \\
20100\end{array}$ & $\begin{array}{l}53.1 \\
46.9\end{array}$ & $\begin{array}{l}2992 \\
1865\end{array}$ & $\begin{array}{l}61.6 \\
38.4\end{array}$ \\
\hline $\begin{array}{l}\text { Region } \\
\text { Zhubei (rural north) } \\
\text { Beipu (rural north) } \\
\text { Ermei (rural north) } \\
\text { Guanxi (rural north) } \\
\text { Danei (rural south) } \\
\text { Jibei (rural south) } \\
\text { DongGang (rural south) } \\
\text { Jiuru (rural south) } \\
\text { Mengjia (urban north) } \\
\text { Dadaocheng (urban north) }\end{array}$ & $\begin{array}{c}6487 \\
6293 \\
3323 \\
12224 \\
5716 \\
942 \\
2083 \\
1845 \\
1934 \\
2039\end{array}$ & $\begin{array}{c}15.1 \\
14.7 \\
7.8 \\
28.5 \\
13.3 \\
2.2 \\
4.9 \\
4.3 \\
4.5 \\
4.8\end{array}$ & $\begin{array}{c}830 \\
1072 \\
588 \\
797 \\
322 \\
70 \\
49 \\
49 \\
400 \\
680\end{array}$ & $\begin{array}{c}17.1 \\
22.1 \\
12.1 \\
16.4 \\
6.6 \\
1.4 \\
1.0 \\
1.0 \\
8.2 \\
14.0\end{array}$ \\
\hline
\end{tabular}




\section{Results}

\section{The effect of adoption for child mortality}

To gain an understanding of the differences of the mortality levels of non-adopted and adopted children, young child mortality risks (between age one and five) are calculated first. Figure 2 presents a KaplanMeier curve for the mortality risk in days from age one until age five for non-adopted and adopted boys and girls separately. Over time, mortality risks increase for all groups, but there is a large difference between non-adopted and adopted children of both sexes. At age five the differences between the groups are largest, with mortality risks for non-adopted girls being $10 \%$, non-adopted boys $9 \%$, and adopted girls and boys $14 \%$. Moreover, these differences are statistically significant.

Next to possible gender differences, regional variation is explored, as many studies have shown that in northern Taiwan adoption was much more common compared to southern Taiwan. Therefore, the Kaplan-Meier curves for mortality risks by region are shown for non-adopted and adopted children in each of the regions separately in Figure 3. A first observation is the regional difference of mortality risks, which is in line with previous studies demonstrating that mortality was much higher in southern Taiwan (Barclay, 1954; Shepherd, 2011). Despite the regional differences in mortality risks, adopted children had higher mortality risks in both regions. In northern Taiwan non-adopted children faced mortality risks of $8 \%$ compared to $13 \%$ for adopted children, in southern Taiwan child mortality risks were $14 \%$ for non-adopted children, compared to $21 \%$ for adopted children.

These univariate results demonstrate that being adopted was important for determining child mortality risks. When differentiating between gender and region the same differences are observed. To be able to look in more detail, and to take co-variates into account, the results of the Cox proportional hazard models are presented by gender and region in Table 2 . The analyses confirm that adopted boys and girls had much higher mortality risks compared to non-adopted children. Adopted boys experienced higher mortality risks compared to adopted girls in both regions. This effect can be found in every region, although the size of the effects differs somewhat. In rural northern Taiwan adoption caused the greatest increase in mortality risks for girls, while for boys the same observation can be made for rural southern Taiwan. $^{9}$

To examine whether the described negative effect of adoption on child mortality is the result of a conscious or unconscious process, it helps to address the differences between adopted boys and adopted girls. In general, an adopted boy was treated well as he was seen as very valuable, especially when a couple invested years of savings in acquiring him. It can therefore be argued that they would

\footnotetext{
${ }^{9}$ Pasternak (1983) wrote that in southern Taiwan, because fewer people wanted to adopt a girl, households had greater choice: in southern Taiwan adopted girls did indeed have lower mortality risks compared to northern Taiwan. However, it is unclear if this is really caused by more supply causing only the healthiest girls to be adopted.
} 
also do everything in their power to keep him alive. In contrast, although families also invested in an adopted girl, she was seen as inferior because of the patriarchal system and practice of son preference. Adopted girls also had to endure more, physically and emotionally, than non-adopted girls. ${ }^{10}$ Therefore, if the negative consequences were the result of a conscious process, one would expect that adoption would have the largest negative effect on female child mortality risks. However, as both sexes experienced higher child mortality risks when adopted before the age of one, it can be argued that the reason for higher child mortality risks of adopted children is probably not related to negative effects because of abuse and malnutrition alone.

A better explanation may be that very young adopted children are in many cases selected - most likely negatively - to be adopted as they come from lower social economic status or farming families, and were given away for adoption because older same-sex siblings or similarly aged siblings were present in their household (Riswick and Lin, 2019). ${ }^{11}$ For example, one would not expect that boys actually experienced higher mortality risks when being adopted. At first this observation seems strange and paradoxical, but it may actually be the result of their perceived value. It is highly plausible that parents adopting a boy, who was very difficult to obtain, were less concerned about his health since supply was limited. Moreover, adopted boys were sometimes also offered through a travelling gobetween who arranged these adoptions, and people complained that many of these boys were sick or weaker than the average child. In short, the (negative) selection of who was given away for adoption may also have caused adopted boys and girls to be somewhat weaker on average. ${ }^{12}$

In sum, when looking specifically at mortality risks of children adopted as infants, it is most likely that the process of adoption itself caused adopted children to have higher mortality risks compared to their non-adopted counterparts. Although from a pure theoretical model all kinds of psychological negative consequences can be imagined, often described as an 'adoption trauma', when infants are taken away from their mothers, early weaning might be the most important direct result. In most localities in Taiwan long breastfeeding was the norm, and adoption could disturb this practice and possibly have major consequences. Older children in turn could already have developed a better immune system and were less vulnerable for infections and other diseases, which might also be the reason why Mattison et

\footnotetext{
${ }^{10}$ For example, everyday expressions underscore the negative view of an adopted girl: a girl with a sullen expression, a crying girl, and a complaining girl were all compared with an adopted little daughter-in-law. Furthermore, interviewed women note that an adopted daughter is more useful because they can push her more to work harder than they would do with their own daughter. Besides working harder, most of the time adopted daughters also got less food and care (Wolf 1972).

${ }^{11}$ Wolf (1995) argues that sickly children were probably not taken in as families often had the chance to inspect the prospective child for adoption. That these children did not show any signs of sickness/weakness, however, does not mean that they may not be negatively selected.

${ }^{12}$ Pasternak (1983: 140) also mentions this selection and goes one step further to argue that "If adopted girls were weaker children to begin within Haishan, then removing those adopted after age one could exaggerate the success of daughters". This may also be one of the reasons why recent studies Mattison et al. (2015, 2018), which select only children adopted between six months and fifteen years old, find different results.
} 
al. (2015) find different results over the life course of children adopted between six months and fifteen years old.

Figure 2: Kaplan-Meier survival curve for non-adopted and adopted boys and girls (1-5 years) in Taiwan, 1906-1945

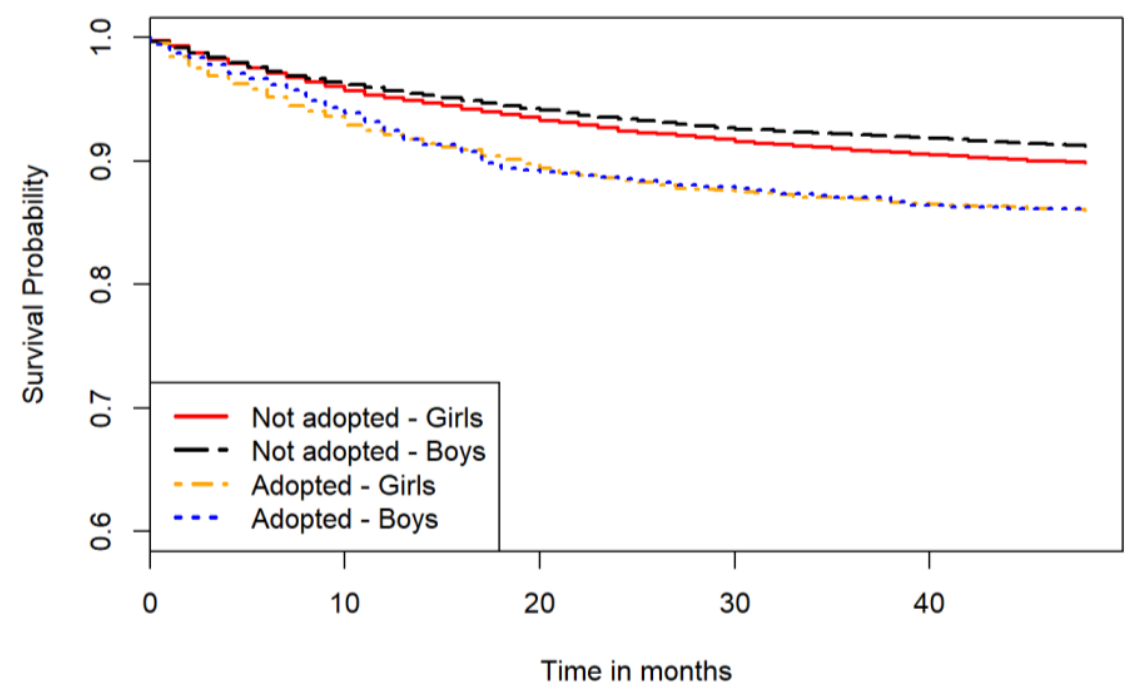

Figure 3: Kaplan-Meier survival curve for non-adopted and adopted children (1-5 years) in northern and southern Taiwan, 1906-1945

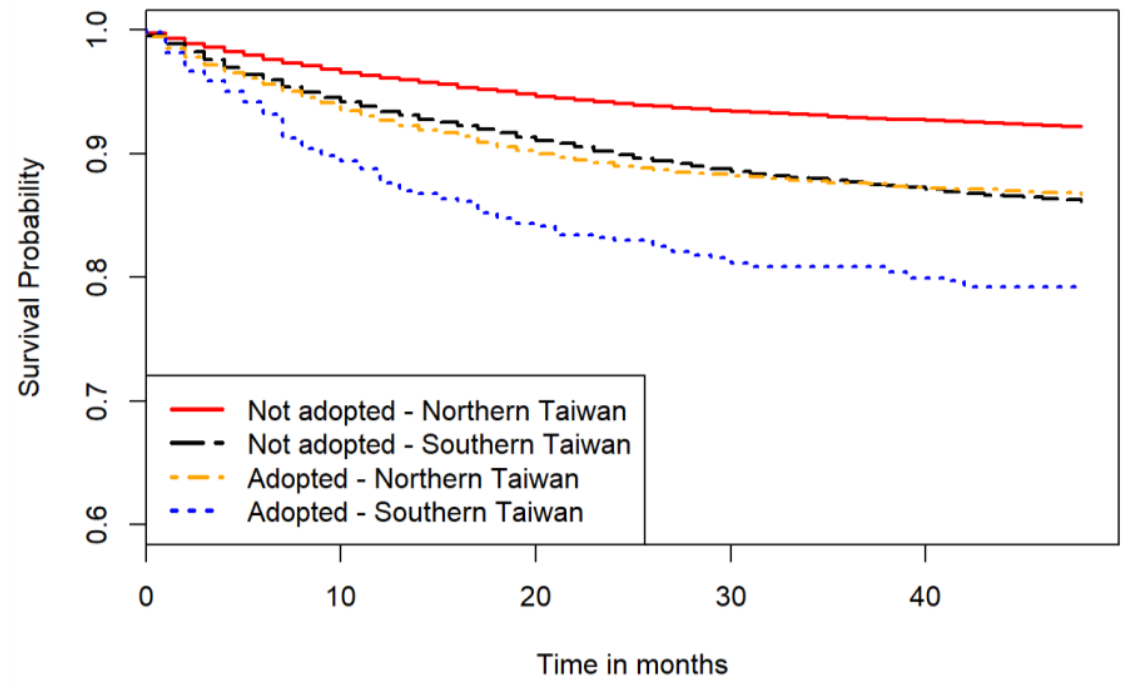


Table 2: Cox proportional hazard models for child mortality (1-5 years) in Taiwan, 1906-1945

\begin{tabular}{|c|c|c|c|c|c|c|}
\hline Area & Gender & Variable & $\begin{array}{l}\operatorname{Exp}(\text { coef }) \\
\end{array}$ & SE & CI & $\mathbf{P}$ \\
\hline \multirow[t]{2}{*}{ Taiwan } & Girls & $\begin{array}{l}\text { Adopted } \\
\text { No } \\
\text { Yes }\end{array}$ & $\begin{array}{l}\text { Ref. } \\
1.492\end{array}$ & 0.053 & $1.342-1.658$ & 0.000 \\
\hline & Boys & $\begin{array}{l}\text { Adopted } \\
\text { No } \\
\text { Yes } \\
\end{array}$ & $\begin{array}{l}\text { Ref. } \\
1.666 \\
\end{array}$ & 0.107 & $1.350-2.056$ & 0.000 \\
\hline \multirow[t]{2}{*}{ Northern } & Girls & $\begin{array}{l}\text { Adopted } \\
\text { No } \\
\text { Yes }\end{array}$ & $\begin{array}{l}\text { Ref. } \\
1.562\end{array}$ & 0.065 & $1.374-1.776$ & 0.000 \\
\hline & Boys & $\begin{array}{l}\text { Adopted } \\
\text { No } \\
\text { Yes } \\
\end{array}$ & $\begin{array}{l}\text { Ref. } \\
1.783 \\
\end{array}$ & 0.150 & $1.328-2.394$ & 0.000 \\
\hline \multirow[t]{2}{*}{ Southern } & Girls & $\begin{array}{l}\text { Adopted } \\
\text { No } \\
\text { Yes }\end{array}$ & $\begin{array}{l}\text { Ref. } \\
1.391\end{array}$ & 0.128 & $1.082-1.788$ & 0.003 \\
\hline & Boys & $\begin{array}{l}\text { Adopted } \\
\text { No } \\
\text { Yes } \\
\end{array}$ & $\begin{array}{l}\text { Ref. } \\
1.848 \\
\end{array}$ & 0.233 & $1.169-2.921$ & 0.008 \\
\hline \multirow[t]{2}{*}{ Taipei } & Girls & $\begin{array}{l}\text { Adopted } \\
\text { No } \\
\text { Yes } \\
\end{array}$ & $\begin{array}{l}\text { Ref. } \\
1.496\end{array}$ & 0.295 & $0.838-2.669$ & 0.172 \\
\hline & Boys & $\begin{array}{l}\text { Adopted } \\
\text { No } \\
\text { Yes }\end{array}$ & $\begin{array}{l}\text { Ref. } \\
1.556\end{array}$ & 0.271 & $0.751-3.222$ & 0.233 \\
\hline
\end{tabular}

Note: In the models, socio-economic status, ethnicity, region, and time period are controlled for. Although there were no differences in the direction and magnitude for the effect of adoption for gender, it was still considered desirable that this study should show the results for girls and boys separately to strengthen the explanation for differences, as, culturally, adopted boys were seen very differently compared to adopted girls, which suggests that the negative effect of adoption is unconscious. An interaction with adoption and sex was not statistically significant, confirming the observation.

\section{The importance of household composition and regional context for the health of adopted children}

To investigate possible factors influencing the negative consequences of adoption further, in this section the influence of differences in household composition and regional context, especially sibship composition, on child mortality risks for adopted children are studied. This might be especially important if the detrimental effects of adoption may be countered by having sufficient resources available. Yet, the opposite may also be true when other children were already present, or when new children were born, as this (unconsciously) resulted in parents and other household members reallocating their time and other resources. In other words, if conditions after adoption were important for child mortality risks, to what extent did the structure of the household play a role?

Previous research has demonstrated that the effect of sibling composition on mortality outcomes may differ depending on the age, sex, and adoption status of siblings (Fox et al., 2017; Kippen and Walters, 2012; Riswick, 2018). A Cox proportional hazard model for female and male child mortality by sibling composition is therefore presented in Table 3. It determines to what extent they compete for 
similar resources or if they may provide support. The results indicate that sibling composition matters for child mortality for adopted children, and that the effects are gendered in the sense that they confirm to the gender bias of son preference. For adopted girls the presence of sisters up to five years older, and adopted sisters more than five years older, and brothers up to five years older increases mortality risks. It demonstrates how adopted girls suffered when younger children were present who needed attention, care and other resources. In contrast, the presence of brothers more than five years older and the presence of a grandfather decreased mortality risks for adopted girls, which might be an indication of the positive effect of the remunerative resources they could bring into the household. This is only relevant for the most vulnerable children, such as female adopted children, because when there is more to go around they will benefit, as sons will always receive the resources they need and girls will suffer when resources are limited.

For boys, only the presence of non-adopted brothers up to five years older increased mortality risks. This suggests that parents did indeed value an adopted boy more compared to other children in the sense that the current household composition did not affect the resources allocated to him. An exception was when a younger brother was born as this increased mortality risks. This can possibly be explained by the fact that most couples who adopted a boy did not expect to have a (or another) son by themselves. The birth of a son could therefore change the position of an adopted boy in the household considerably. Higher mortality risks most likely reflect a reallocation of resources to the newborn son. Even so, these results should be read with caution because of the relatively low number of observations for adopted boys.

Table 3: Cox proportional hazard models for child mortality (1-5 years) by sex in Taiwan, 1906-1945

\begin{tabular}{|l|c||c|}
\hline \hline & Adopted girls (1-5 years) & Adopted boys (1-5 years) \\
\hline Variable & Exp(coef) & Exp(coef) \\
\hline \hline Brother(s) 5 years older present & $0.901+$ & 0.715 \\
& $(0.793-1.023)$ & $(0.344-1.488)$ \\
\hline Brother(s) up to 5 years older present & $1.482^{* * * *}$ & $2.289 * *$ \\
& $(1.236-1.776)$ & $(1.171-4.473)$ \\
\hline Adopted brother(s) 5 years older present & 1.423 & 0.536 \\
& $(0.856-2.367)$ & $(0.128-2.230)$ \\
\hline Adopted brother(s) up to 5 years older present & 0.639 & 2.194 \\
& $(0.317-1.287)$ & $(0.732-6.575)$ \\
\hline Sister(s) 5 years older present & 0.977 & 0.684 \\
& $(0.776-1.230)$ & $(0.392-1.194)$ \\
\hline Sister(s) up to 5 years older present & $1.384 * * *$ & 1.037 \\
& $1.114-1.719$ & $(0.581-1.851)$ \\
\hline Adopted sister(s) 5 years older present & $1.337 * * *$ & 1.087 \\
& $(1.074-1.666)$ & $(0.695-1.702)$ \\
\hline
\end{tabular}




\begin{tabular}{|l||c||c|}
\hline Adopted sister(s) up to 5 years older present & $\begin{array}{c}1.193 \\
(0.842-1.692)\end{array}$ & $\begin{array}{c}0.992 \\
(0.579-1.699)\end{array}$ \\
\hline Mother present & 0.851 & 0.996 \\
& $(0.601-1.205)$ & $(0.552-1.796)$ \\
\hline Father present & 0.844 & 1.137 \\
& $(0.605-1.177)$ & $(0.602-2.149)$ \\
\hline Grandmother present & 0.966 & 0.763 \\
& $(0.793-1.176)$ & $(0.489-1.192)$ \\
\hline Grandfather present & $0.822+$ & 1.313 \\
& $(0.652-1.035)$ & $(0.813-2.121)$ \\
\hline
\end{tabular}

Note: In the models for Taiwan, socio-economic status, region, time period and adoption age are controlled for. The same models were run for all children who were adopted before age five, starting from the moment of adoption until death or age five. By doing so, a larger number of adopted children can be observed from the exact moment of adoption onwards, instead of from age one. In this way, a better indication can be given for the effect of different household compositions directly after adoption. The results of these models (available upon request) were, however, similar in direction and effect, which demonstrates their robustness. Presented are the hazard rates,

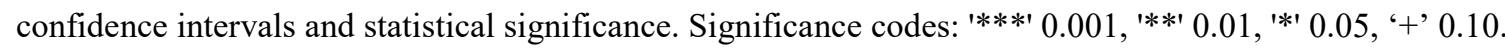

To investigate the possible regional differences of the effect of household composition on child mortality for adopted girls, Cox proportional hazard models for female child mortality are presented by region in Table $4 .{ }^{13}$ Although not always statistically significant, in general for rural northern and southern Taiwan similar findings are found in the direction and sizes of the mortality risks. One difference is that adopted sisters who are five years or more older increased mortality risks in northern Taiwan. This is in line with previous findings for non-adopted girls and could be connected to the fact that adopted sisters would compete with each other for similar resources. For urban northern Taiwan, however, some differences with the two other regions are found. Only non-adopted sisters who are five years or more older increase mortality risks. In the city older daughters might already be able to bring in additional income to the family, and due to this receive more resources because they were perceived as valuable (Wolf and Gates, 2005).

\footnotetext{
${ }^{13}$ This is only done for girls because the limited number of boys does not make it possible to investigate regional differences.
} 
Table 4: Cox proportional hazard models for female child mortality (1-5 years) by region in Taiwan, 1906-1945

\begin{tabular}{|c|c|c|c|}
\hline Variables & Northern Taiwan & Southern Taiwan & Taipei \\
\hline Brother(s) 5 years older present & $\begin{array}{c}0.872+ \\
(0.750-1.014)\end{array}$ & $\begin{array}{c}0.671+ \\
(0.430-1.046)\end{array}$ & $\begin{array}{c}1.018 \\
(0.747-1.385)\end{array}$ \\
\hline Brother(s) up to 5 years older present & $\begin{array}{c}1.617^{* * * *} \\
(1.289-2.028)\end{array}$ & $\begin{array}{c}1.724+ \\
(0.964-3.079)\end{array}$ & $\begin{array}{c}1.033 \\
(0.691-1.543)\end{array}$ \\
\hline Adopted brother(s) 5 years older present & $\begin{array}{c}1.941 * * \\
(1.173-3.212)\end{array}$ & & \\
\hline Adopted brother(s) up to 5 years older present & $\begin{array}{c}0.582 \\
(0.239-1.417)\end{array}$ & & \\
\hline Sister(s) 5 years older present & $\begin{array}{c}0.804 \\
(0.598-1.081)\end{array}$ & $\begin{array}{c}1.236 \\
(0.689-2.234)\end{array}$ & $\begin{array}{r}1.596+ \\
(0.976-2.611)\end{array}$ \\
\hline Sister(s) up to 5 years older present & $\begin{array}{c}1.356^{*} \\
(1.040-1.767)\end{array}$ & $\begin{array}{c}1.725+ \\
(0.951-3.125)\end{array}$ & $\begin{array}{c}1.305 \\
(0.784-2.171)\end{array}$ \\
\hline Adopted sister(s) 5 years older present & $\begin{array}{c}1.420 * * \\
(1.090-1.850)\end{array}$ & $\begin{array}{c}0.672 \\
(0.209-2.165)\end{array}$ & $\begin{array}{c}1.168 \\
(0.728-1.873)\end{array}$ \\
\hline Adopted sister(s) up to 5 years older present & $\begin{array}{c}1.391+ \\
(0.944-2.051)\end{array}$ & $\begin{array}{c}2.758 \\
(0.275-2.759)\end{array}$ & $\begin{array}{c}0.740 \\
(0.320-1.712)\end{array}$ \\
\hline Mother present & $\begin{array}{c}1.095 \\
(0.662-1.811)\end{array}$ & $\begin{array}{r}1.041 \\
(0.326-3.323)\end{array}$ & $\begin{array}{c}0.548^{*} \\
(0.315-0.953)\end{array}$ \\
\hline Father present & $\begin{array}{c}0.708 \\
(0.453-1.107)\end{array}$ & $\begin{array}{c}0.739 \\
(0.261-2.094)\end{array}$ & $\begin{array}{c}0.830 \\
(0.475-1.451)\end{array}$ \\
\hline Grandmother present & $\begin{array}{c}0.887 \\
(0.693-1.135)\end{array}$ & $\begin{array}{c}1.011 \\
(0.612-1.669)\end{array}$ & $\begin{array}{c}1.131 \\
(0.731-1.749)\end{array}$ \\
\hline Grandfather present & $\begin{array}{c}0.845 \\
(0.645-1.107)\end{array}$ & $\begin{array}{c}0.404 * \\
(0.612-0.842)\end{array}$ & $\begin{array}{c}1.232 \\
(0.691-2.197)\end{array}$ \\
\hline
\end{tabular}

Note: In the models, socio-economic status, ethnicity, time period and adoption age are controlled for. In the models for southern Taiwan and Taipei the some variables were not included because the number of observations and deaths were too low to offer any reliable results. Presented are the hazard rates, confidence intervals and statistical significance. Significance codes: '***' $0.001,{ }^{\prime * * \prime} 0.01,{ }^{\prime * \prime} 0.05,{ }^{\prime}+’ 0.10$.

\section{Conclusion and discussion}

Little is known about how the health of children is affected by adoption, especially for historical societies. This study investigated child mortality risks of adopted infants in Taiwan during the period 1906-1945 in order to be able to say something about the consequences of adoption on health. By doing so, it was hoped that the study would give more insight into the process of adoption in a historical nonWestern society. The goal was twofold. Firstly, to investigate if, and how, adoption of infants increased child mortality risks compared to non-adopted children. The study demonstrates that child mortality 
risks of adopted children, both boys and girls, were much higher compared to non-adopted children. Moreover, despite differences in the size of mortality risks, this was true for all regions. This indicates that although economic conditions and cultural norms varied, it did not affect the negative impact of being adopted on child mortality risks. A possible explanation may be the unconscious consequences of the process of adoption itself, in which children were adopted at a very young age. This might in turn be related to early weaning and is consistent with descriptions in ethnographic studies. It confirms our hypothesis that infant adoption causes higher mortality, and suggests that the protective effect that adopted children experience, which was found by other studies as well, occurred at later ages or is only visible for those who were adopted after infancy.

The second goal was to investigate if, and how, household composition after adoption influenced child mortality risks of children adopted as infants. The results demonstrate that household composition was especially important for adopted girls. In particular, similarly aged siblings increased female child mortality risks, indicating that when a sibling who was younger or more than five years older was present, they would suffer the consequences of a reallocation of resources. This was in general true for both rural northern and southern Taiwan, although adopted siblings possibly played a different role in most regions. The differences with Taipei, an urban area, indicate the possible differences of household allocation in this specific (modernising) regional context in which traditional gender roles slowly changed. For adopted boys, only the presence of non-adopted brothers who were younger or up to five years older increased child mortality risks, suggesting competition between them resulting in a reallocation of resources from the adopted child to the non-adopted one.

These results demonstrate that household composition is as important for adopted children as for non-adopted children (see for the study on the impact of household composition on non-adopted child mortality Riswick and Hsieh (forthcoming)). It confirms the idea that household composition after adoption also mattered for child survival of adopted children, especially girls, next to the fact of being adopted or not. As adopted children were always the youngest members of the household at the time of adoption, it was they in particular who faced resource dilution when a new child entered the household through birth or adoption who -due to the closeness in age - competed for comparable resources. It confirms the idea that the entrance of another younger child 'dethroned' the older sibling. Younger children who needed to be nursed competed directly with recently weaned children as they monopolized much of a mother's time and attention (Kramer et al., 2016; Wolf, 1995). Furthermore, it is clear that this effect is gendered, which can be explained by the fact that Chinese society valued, and in turn protected, adopted boys more than adopted girls from other, especially younger, siblings, who might have been present. Moreover, in practice this meant that many adopted girls were weaned at a relatively early age. Some of those nursed by their foster mothers probably even had to share their breasts with their future husband. As a result the great majority suffered from competition with their foster families' own sons and daughters. 
In summary, the findings of this study underscore that household composition after adoption should be taken into account when investigating mortality risks. Regional context may play a role in determining the allocation of resources between household members, which in turn affects child mortality risks. At the same time, however, in all regional contexts infant adoption increase child mortality risks, indicating that this effect is not context-specific. This is important for understanding how inequalities in health were shaped in the past, but may also give an indication of how adoption, and household composition after adoption, may influence other forms of health/social inequalities (albeit ones less extreme than death). Nevertheless, there are several limitations of this study. It would be best to be able to follow adopted children from birth to death and not from adoption onwards, to really be able to take into account the early life conditions of adopted children and the exact timing of their adoption. This is at the moment only possible for a small number of adoptions taking place within the same area. ${ }^{14}$ In addition, in the future, the role of other factors that may influence the division of resources after adoption should be taken into account. For instance, household members - besides siblings, parents and grandparents - should also be investigated to see whether they matter for the mortality risks of adopted children as well. At this moment only a limited part of the extended family is taken into account.

\footnotetext{
${ }^{14} \mathrm{Next}$ to only having a very small sample, this kind of adoption may also not be representative because the family of the adopted child lives relatively nearby. This may, at least theoretically, also affect the mortality risks of adopted children because it may influence caretaking behaviour.
} 


\section{References}

Barclay, G.W., 1954. Colonial development and population in Taiwan. Princeton University Press, Princeton, New Jersey.

Bras, H., Kok, J., Mandemakers, K., 2010. Sibship size and status attainment across contexts: Evidence from the Netherlands, 1840-1925. Demogr. Res. 23, 73-104. https://doi.org/10.4054/DemRes.2010.23.4

Brown, A., Waters, C.S., Shelton, K.H., 2017. A systematic review of the school performance and behavioural and emotional adjustments of children adopted from care. Adopt. Foster. 41, 346-368. https://doi.org/10.1177/0308575917731064

Campbell, C., Lee, J.Z., 2004. Mortality and Household in Seven Liaodong Populations, 1749-1909, in: Bengtsson, T., Campbell, C., Lee, J.Z., et al. (Eds.), Life under Pressure: Mortality and Living Standards in Europe and Asia, 1700-1900. The MIT Press, Cambridge \& London, pp. 293-324.

Chuang, Y.-C., Wolf, A.P., 1995. Marriage in Taiwan, 1881-1905: An example of regional diversity. J. Asian Stud. 54, 781-795.

Derosas, R., Oris, M., 2002. When dad died. Individuals and Families Coping with Family Stress in Past Societies. Peter Lang, Bern.

Dong, H., Campbell, C., Kurosu, S., Yang, W., Lee, J.J.Z., 2015. New Sources for Comparative Social Science: Historical Population Panel Data From East Asia. Demography 52, 1061-1088. https://doi.org/10.1007/s13524-015-0397-y

Dong, H., Kurosu, S., 2019. Long Live (for) the Family: Gendered Survival Differentials between Adopted and Biological Children in Northeastern Japan, 1708-1870.

Downey, D.B., 2001. Number of siblings and intellectual development: The resource dilution explanation. Am. Psychol. 56, 497-504.

Engelen, T.L.M., Wolf, A.P., 2006. Fertility four ways. Dutch urban and rural and Taiwanese urban and rural, in: Chuang, Y.-C., Engelen, T.L.M., Wolf, A.P. (Eds.), Positive or Preventive? Reproduction in Taiwan and the Netherlands 1850-1940. Aksant, Amsterdam, pp. 107-120.

Fauve-Chamoux, A., 1998. Introduction: Adoption, affiliation, and family recomposition-inventing family continuity. Hist. Fam. 3, 385-392. https://doi.org/10.1016/S1081-602X(99)80253-X

Feng, W., Lee, J., 1998. Adoption among the Qing nobility and its implications for Chinese demographic behavior. Hist. Fam. 3, 411-427. https://doi.org/10.1016/S1081-602X(99)80255-3

Folbre, N., 1986. Hearts and Spades: Paradigms of Household Economics. World Dev. 14, 245-255.

Fox, J., Willführ, K.P., Gagnon, A., Dillon, L., Voland, E., 2017. The consequences of sibling rivalry on survival and reproductive success across different ecological contexts : a comparison of the historical Krummhörn and Quebec populations. Hist. Fam. 22, 364-423. https://doi.org/10.13140/RG.2.1.3986.9200

Gates, H., 1987. Chinese working-class lives: Getting by in Taiwan. Cornell University Press, Ithaca \& London.

Gibbs, B.G., Workman, J., Downey, D.B., 2016. The (Conditional) Resource Dilution Model: State- and Community-Level Modifications. Demography 53, 723-748. https://doi.org/10.1007/s13524-016-0471-0

Gibson, K., 2009. Differential parental investment in families with both adopted and genetic children. Evol. Hum. Behav. 30, 184-189. https://doi.org/10.1016/j.evolhumbehav.2009.01.001

Goody, J., 1969. Adoption in Cross-Cultural Perspective Adoption in Cross-Cultural Perspective. Comp. Stud. Soc. Hist. 11, 55-78.

Howell, S., 2009. Adoption of the Unrelated Child: Some Challenges to the Anthropological Study of Kinship. Annu. Rev. Anthropol. 38, 149-166. https://doi.org/10.1146/annurev.anthro.37.081407.085115

Kalmijn, M., van de Werfhorst, H.G., 2016. Sibship Size and Gendered Resource Dilution in Different Societal Contexts. PLoS One 11. https://doi.org/10.1371/journal.pone.0160953

Kippen, R., Walters, S., 2012. Is Sibling Rivalry Fatal? Siblings and Mortality Clustering. J. Interdiscip. Hist. 42, 571-591.

Klep, P.M.M., 2004. Introduction to special issue: contradictory interests of offspring and parents, 1500-2000. Hist. Fam. 9, 349-354.

Kramer, K.L., 2010. Cooperative Breeding and its Significance to the Demographic Success of Humans. Annu. Rev. Anthropol. 39, 417-436. https://doi.org/10.1146/annurev.anthro.012809.105054

Kramer, K.L., Veile, A., Otárola-castillo, E., 2016. Sibling Competition \& Growth Tradeoffs . Biological vs . Statistical Significance 1-17. https://doi.org/10.1371/journal.pone.0150126

Kurosu, S., Ochiai, E., 1995. Adoption as an heirship strategy under demographic constraints: a case from nineteenth-century Japan. J. Fam. Hist. 20, 261-288.

Li, C., Yang, W.-S., Chuang, Y.-C., 2011. How reliable is Taiwan's colonial period demographic data. An empirical study using demographic indirect estimation techniques, in: Engelen, T., Shepherd, J.R., Yang, W.-S. (Eds.), Death at the Opposite Ends of the Eurasian Continent Mortality Trends in Taiwan and the Netherlands. Aksant, Amsterdam, pp. 349-376.

Lin, X.C., 2011. Female Heads of Households in Eurasian Societies. Taipei and Rotterdam in times of 
industrialisation. Radboud University, Nijmegen.

Mattison, S.M., Brown, M.J., Floyd, B., Feldman, M.W., 2015. Adoption Does Not Increase the Risk of Mortality among Taiwanese Girls in a Longitudinal Analysis. PLoS One 10, 1-18. https://doi.org/10.1371/journal.pone.0122867

Mattison, S.M., Seabright, E., Adam, Z., Cao, J.B., Brown, M.J., Feldman, M.W., 2018. Adopted daughters and adopted daughters-in-law in Taiwan : a mortality analysis Subject Category: R. Soc. Open Sci. 5, 1-15.

Öberg, S., 2017. Too many is not enough: studying how children are affected by their number of siblings and resource dilution in families. Hist. Fam. 22, 157-174. https://doi.org/10.1080/1081602X.2017.1302890

Olds, K.B., 2006. Female productivity and mortality in early-20th-century Taiwan. Econ. Hum. Biol. 4, 206 221. https://doi.org/10.1016/J.EHB.2005.12.002

Oris, M., Derosas, R., Breschi., M., Breschi, M., others, 2004. Infant and child mortality, in: Bengtsson, T., Campbell, C., Lee, J.Z. (Eds.), Life Under Pressure: Mortality and Living Standards in Europe and Asia, 1700-1900. MIT Press, Cambridge, pp. 359-398.

Palacios, J., Brodzinsky, D., 2010. Adoption research: Trends, topics, outcomes. Int. J. Behav. Dev. 34, 270 284. https://doi.org/10.1177/0165025410362837

Pasternak, B., 1983. Guests in the dragon: social demography of a Chinese district 1895-1946. Columbia University Press, New York.

Riswick, T., 2018. Testing the conditional resource-dilution hypothesis: the impact of sibship size and composition on infant and child mortality in the Netherlands, 1863-1910. Hist. Fam. 23, 623-655. https://doi.org/10.1080/1081602X.2018.1532310

Riswick, T., 2013. Gevangen tussen cultuur en biologie. De invloed van gender en adoptie op kindersterfte in de Taiwanese familie in Hai-shan, 1906-1945, in: Matthijs, K., Puschmann, P., Bras, H., Janssens, A. (Eds.), Gender In/en Historische Demografie. Historisch-Demografisch Onderzoek in Vlaanderen En Nederland. Acco, Leuven, pp. 71-102.

Riswick, T., Engelen, T., 2018. Siblings and life transitions: investigating the resource dilution hypothesis across historical contexts and outcomes. Hist. Fam. 23. https://doi.org/10.1080/1081602X.2018.1532309

Riswick, T., Hsieh, Y.-H., forthcoming. Between Rivalry and Support: The Impact of Sibling Composition on Infant and Child Mortality in Taiwan, 1906-1940.

Riswick, T., Lin, X.C., 2019. Causes of Child Adoption in Taiwan, 1906-1940: The Importance of Gender, Household Composition and Variation over Time and Place. SocArXiv. https://doi.org/doi:10.31235/osf.io/4jb3u.

Santos-Nunes, M., Narciso, I., Vieira-Santos, S., Roberto, M.S., 2018. Adoptive versus Mixed Families: Child Adjustment, Parenting Stress and Family Environment. J. Child Fam. Stud. 27, 1858-1869. https://doi.org/10.1007/s10826-018-1019-2

Saso, M.R., 1999. Velvet bonds: the Chinese family. New Life Center, Carmel.

Sear, R., Coall, D., 2011. How Much Does Family Matter? Cooperative Breeding and the Demographic Transition. Popul. Dev. Rev. 37, 81-112. https://doi.org/10.1111/j.1728-4457.2011.00379.x

Sear, R., Mace, R., 2008. Who keeps children alive? A review of the effects of kin on child survival. Evol. Hum. Behav. 29, 1-18. https://doi.org/10.1016/j.evolhumbehav.2007.10.001

Shepherd, J.R., 2011. Regional and ethnic variation in mortality in Japanese colonial period Taiwan, in: Engelen, T., Shepherd, J.R., Yang, W.-S. (Eds.), Death at the Opposite Ends of the Eurasian Continent: Mortality Trends in Taiwan and the Netherlands, 1850-1945. Aksant, Amsterdam, pp. 99-152.

Skinner, G.W., 1997. Family systems and demographic processes, in: Kertzer, D.I., Fricke, T.E. (Eds.), Anthropological Demography: Toward a New Synthesis. Chicago: University of Chicago Press, pp. 53-95.

Van Poppel, F., 2000. Children in One-Parent Families: Survival as an Indicator of the Role of the Parents. J. Fam. Hist. 25, 269-290. https://doi.org/10.1177/036319900002500301

Waltner, A.B., 1990. Getting an heir: Adoption and the construction of kinship in late imperial China. University of Hawaii Press, Honolulu.

Wolf, A.P., 2005. Europe and China: Two Kinds of patriarchy, in: Engelen, T.L.M., Wolf, A.P. (Eds.), Marriage and the Family in Eurasia. Perspectives on the Hajnal Hypothesis. Aksant, Amsterdam, pp. 215-240.

Wolf, A.P., 1995. Sexual attraction and childhood association: A Chinese brief for Edward Westermarck. Stanford University Press, Stanford.

Wolf, A.P., Gates, H., 2005. Marriage in Taipei city: reasons for rethinking Chinese demography. Int. J. Asian Stud. 2, 111-133.

Wolf, A.P., Huang, C., 1980. Marriage and adoption in China: 1845-1945. Stanford University Press, Stanford.

Wolf, M., 1972. Women and the family in rural Taiwan. Stanford University Press, Stanford.

Yu, G., Huang, Y., Chuu, L., 2011. Illegitimacy, adoption, and mortality among girls in Penghu, 1906-1945, in: Engelen, T., Shepherd, J.R., Wen-Shan, Y., Yang, W.-S. (Eds.), Death at the Opposite Ends of the Eurasian Continent. Aksant, Amsterdam, p. 317-47. 


\section{Appendix}

Figure A1: Number of adoptions in each age (in months) until age five

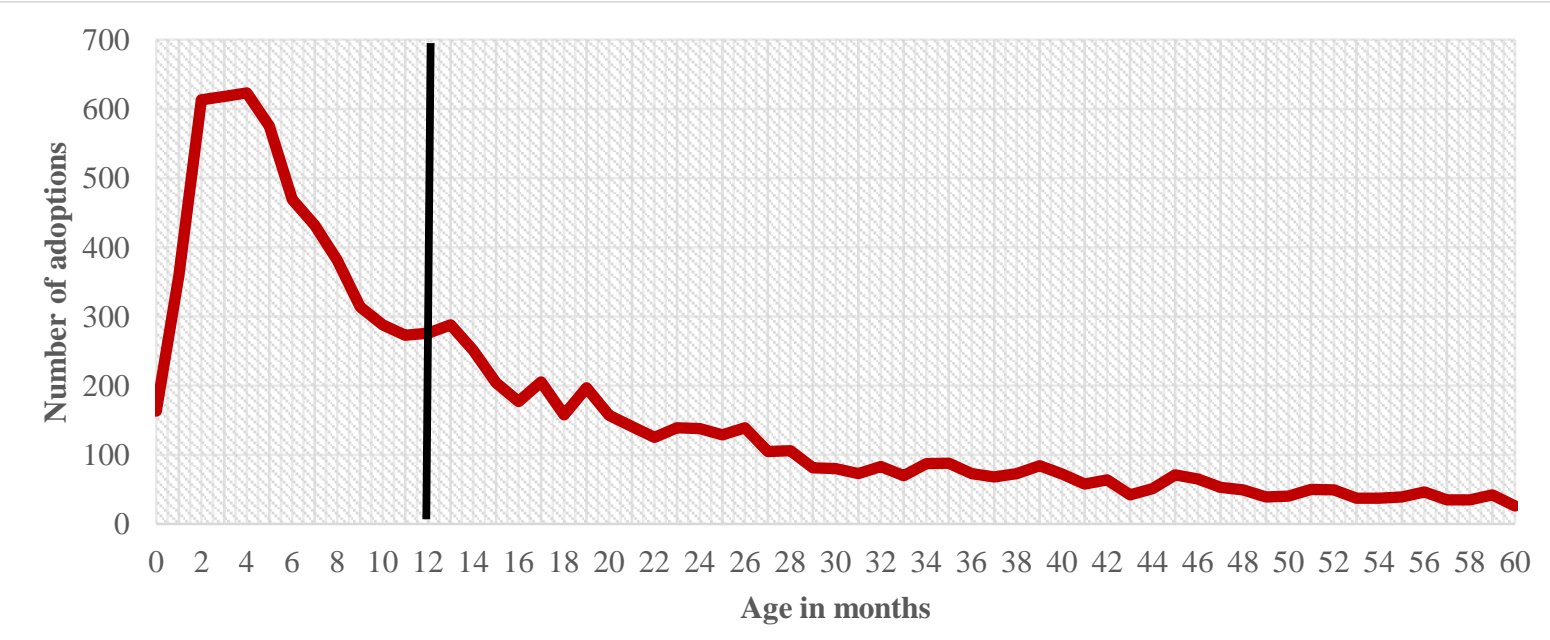

Figure A2: Cumulative percentage of children adopted of children adopted before the age of five

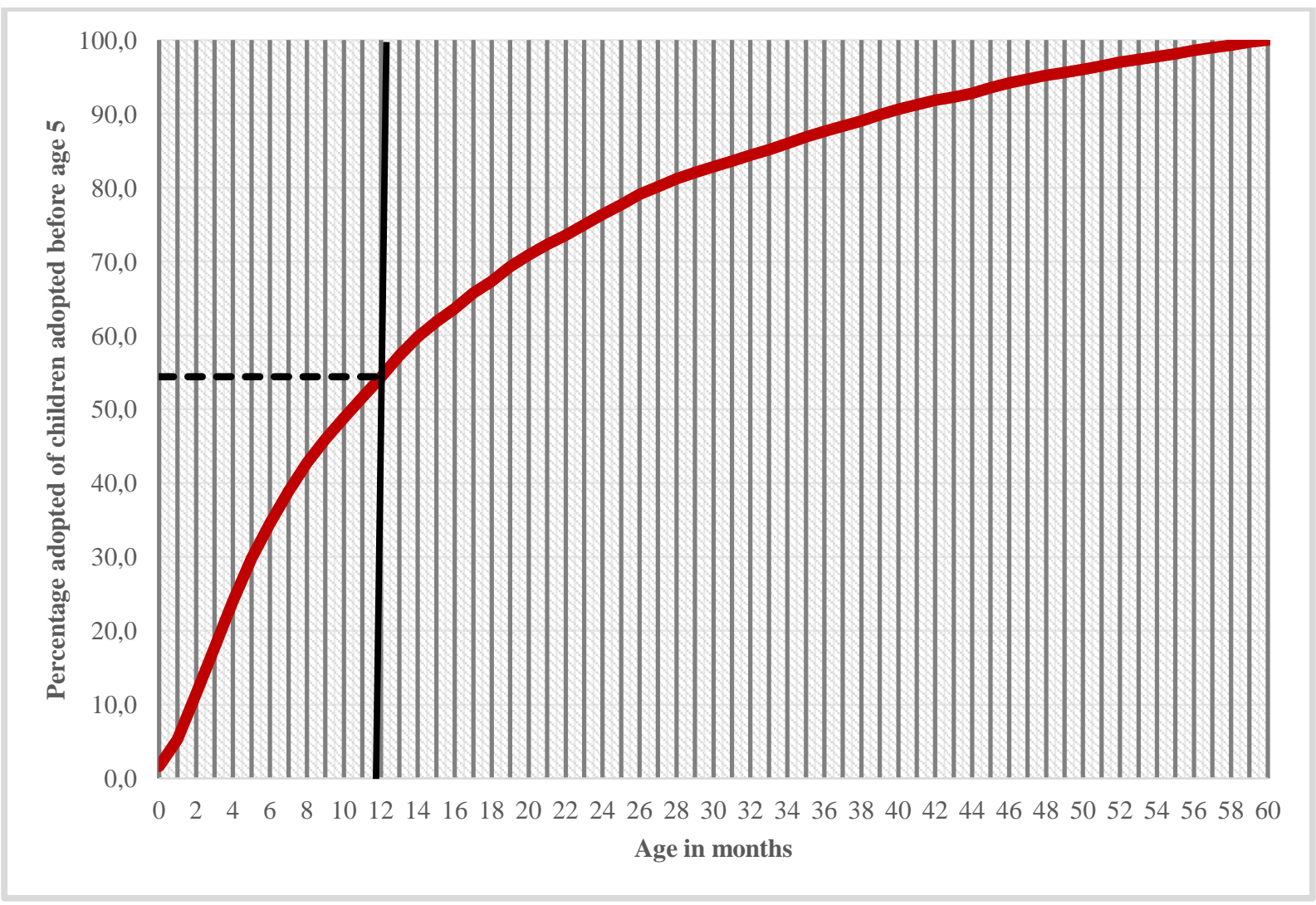

Note: Most adoptions took place before the age of two years old (see Figure A1). When looking at the adoptions before the age of five the mode for the age of adoption is four months, and the median age is eleven months. See also Riswick and Lin (2019) for more information on the adoption process and ages. In our study we chose to only include children who were adopted as infants (as illustrated in Figure A2). 